\title{
The Importance of Power Safety Management
}

\author{
Bai Jiatian, Zhang Fuliang, Wei Ye, Yuan Chengye, Zhao Qidong, Hu Yang, Li Wei, Zhao Yan, \\ Li Huiyan, Wu Yaowei
}

Fushun Power Supply Company, Liaoning Electric Power Company Limited, State Grid, China

\author{
Keywords: Power security; Control; Dispatch; Evaluation
}

\begin{abstract}
The power safety management is interpreted from four aspects: power safety control, power safety dispatch, power safety evaluation and power safety management, which puts forward some problems that should be paid attention to and some measures that can be taken by the point of view of power safety management. Based on the analysis of some common problems in power safety above, this paper expounds power safety management as a whole. Power safety production is not only a complex system engineering, but also the foundation of power enterprises and even the whole society reform, development and stability. The importance of power safety management should be fully recognized.
\end{abstract}

\section{Introduction}

In accordance with certain principles, management is the way in which people organize, direct and coordinate the activities of groups scientifically, so as to achieve the desired goals and the results of individual activities. Safety management means that business operators, production managers and all employees organize, direct and coordinate the activities of all employees in a scientific manner in accordance with certain safety management principles so as to achieve the goals of production safety ${ }^{[1]}$.

\section{Electricity Security Control}

Refers to the manager's determination, investigation, judgment and evaluation of the status of the management object, as compared with the management objective, to identify gaps or problems, to take appropriate measures and to make necessary corrections ${ }^{[2]}$.

\subsection{Security target control}

The security goal is the general goal of power enterprise's annual safety work. It 's not only the general outline of the safety work for one year, but also the final destination of the safety work for the whole year. Therefore, the power security goal must be put forward clearly, to the point, not only in the overall picture, but also to highlight the focus, and has cohesion and appeal.

\subsection{Security responsibility control}

The state stipulates that the official duty of a unit should be the first person who is responsible for his security work. Staffs should sign security letters from top to bottom, and the personnel of the team. It's an administrative, strengthened and effective security responsibility system, which greatly strengthens the overall system of security and safety.

\subsection{Security behaviour control}

This is the key part of power safety management. In order to ensure the safety of people and equipment in power production process, the operator's behavior must be regulated and controlled.

\subsection{Accident risk control}

Accident risk includes two factors: the frequency of the accident and the severity of its consequence. In order to prevent and reduce the occurrence of accidents, electric power enterprises 
should strictly implement a series of technical measures to prevent fire, natural disaster and personal injury. They should strictly carry out emergency repair, regular and state preventive repair or technical reform of power supply equipment, carry out accident hazard survey and safety evaluation of equipment. They should also organize experts to forecast the risk of accidents in enterprises, that means trying to make the enterprise's accident risk value in the minimum.

\section{Electrical safety adjustment}

The safe and stable operation of power grid is one of the important indexes of high quality service in power system. The main task of power dispatch is to direct the power network operation of the turnpike, power network fault and accident, as far as possible to ensure the normal power supply. To ensure power safety scheduling, two key links must be firmly grasped: scheduling operations and accident handling [3].

\section{Electricity dispatch operations}

Power scheduling misoperation not only makes power supply interrupt, power loss, equipment damage, but also has a great impact on the society and users, sometimes even endanger the safety of personnel. It's very important to do well in electricity dispatching to avoid the accident of misdispatching operation. The following things should be done well in electricity dispatching:

(1) Strengthen ideological and safety education and improve the quality of safety activities. Hold the safety meeting of the team regularly, study the higher level of the safety production documents, organize the class to summary the safety situation and analysis the recent accident in the electric power system, aimed at the actual operation of some problems in-depth discussion.

(2) We shall strictly implement the relevant rules and regulations and resolutely oppose any act of sexual inertia. The daily work of power dispatch is based on rules and regulations.

(3) To strengthen technical training and further improve the professional quality of dispatch personnel. Dispatch personnel should continuously learn new technology, new knowledge, improve business skills to be competent in their duties. Only through various forms of hard training, the dispatcher has the ability deal with the accident calmly.

\section{Grid incident handling}

The unexpected and unpredictable accident of power grid brings serious test to the treatment of power grid accident. To deal with the grid incident handling well, the following things should be done. Firstly, to master the rules and regulations and deal with accidents correctly and promptly. Secondly, power dispatch personnel should have good professional and psychological qualities. Thirdly, master the mode of operation and make a correct forecast of the accident. Fourthly, to master the scheme and working principle of power network relay protection and automatic installation, and be able to use them correctly. Fifthly, the operating conditions of the main equipment of the power grid must be known.

\section{Electrical safety evaluation}

Safety evaluation is an important part of safety risk management and a concrete means to realize safety risk management. To carry out safety evaluation, we should know that it's a process of continuous improvement, and we must continue to carry out safety evaluation based on the new situation of safe production and the actual situation of enterprises.

(1) It should have the standard evaluation and the basis of the development. Power enterprises carrying out safety evaluation must adopt new regulations, rules in time so as to adapt to the changing elements of personnel, equipment, environment and management.

(2) There should be an expert group on safety evaluation with rich experience and solid business. The work of safety evaluation is very large, so the experts should have high professional level, 
responsibility and good physical quality. The level of the experts team directly influences the effectiveness of security evaluation.

(3) The content and means of safety evaluation should be continuously enriched. Make the safety evaluation of power supply enterprises with much more vitality. It's necessary to enrich the content of safety evaluation by fully reflecting the evaluation of characters, environment and management factors of safe production.

(4) The relationship between hazard pre-control and safety risk management should be clarified. The safety evaluation must be combined with the safety risk management, and the problems found by the safety evaluation can be incorporated into the risk management system. The new problems found by the risk identification can be expanded into the rectification process of the safety evaluation. Improve the level of safety management of enterprises continuously that make the safe production controlled with possibility, necessity and on-line achieved.

(5) All work should be carried out in an organized and planned manner. Safety evaluation is a systematic static evaluation and a dynamic evaluation of an enterprise production safety management work, which is also an effective safe production management means through the practice. Avoid the movement of development, formalism and comparing how much score processed.

(6) The standards of the state maintenance should be thoroughly understood and the contents and requirements of the safety evaluation should be coordinated. State maintenance is based on the safety, environment and efficiency of the enterprise. The maintenance work is carried out by means of status assessment, risk analysis and maintenance decision. The aim of the state maintenance is to improve the reliability of the equipment and the safe operation level of the power network so as to strengthen the detection and monitor the state of the equipment.

\section{The Relationship to be Grasped in Power Safety Production Management}

The work of power safety is complexity. In specific work, it is useful to grasp the major and minor problems and keep pace with the priorities so as to deal with the common situations in safe production management ${ }^{[4]}$.

The relationship between management and technology, personnel and equipment, leadership and employees.

1) Management and technology.

Management is more important than technology for the survival of an enterprise. In the practice of safe production, the technology must obey the management needs and serve the safe production. And management also needs to organize technology research and training based on the needs of technology application, so as to give full play to the advantages of technology promoting production management.

2) Personnel and equipment. Personnel is the main body of safe production practice; equipment is the object. The equipment can play a role through the human management, use and maintenance.

3) Leadership and staff. The leader is the decision maker because of his resources. The staff is the executive. Leadership and execution are equally important in managing safe production.

The relationship between deployment and inspection, objectives and feedback. Deploying only without checking is an open loop management method, the deployment requirements are difficult to fully implement, post-deployment inspection, which is the key to the implementation of the requirements. How to check effectively, how to get real information and whether the problem can be corrected in time are the key goals we need to solve. After the target is determined, information feedback is the key to the normal regulation of the closed-loop system. In the work, we should pay attention to the management of feedback information, especially to ensure the authenticity of feedback information, so as to avoid the distortion of information caused by interference.

\section{Conclusions}

This paper expounds power safety management as a whole through the analysis of several 
common problems in power safety. Power safety production is not only a complex system engineering, but also the foundation of power enterprises and even the whole society reform, development and stability. We should fully recognize the importance of power safety management. Only by increasing the strength of safety management and improving the level of power safety management can we ensure that all requirements for safe production are implemented.

\section{References}

[1] Liu Jiacheng: Three functions of power safety management. Power security technology[J],2005.

[2] Wang Jianjun: The discussion of power safety dispatch. Introduction to technology and innovation [J], 2011.4

[3] Li Shibo. Daily fault analysis and resolution of leakage protectors[J]. Communications World 2007.

[4] Zhao Shaofeng, Shi Yubo. Brief discussion on the ways of safe operation of power dispatching [J], Electronic Technology, 2011(5). 